Products and Services In Practice is provided to readers using text and images from the manufacturer, supplier or distributor and does not imply endorsement by $B D J$ In Practice. Normal and prudent research should be exercised before purchase or use of any product mentioned.

Please send product and services news through to David Westgarth, BDJ In Practice via: bdjinpractice@bda.org

\section{More than an \\ equipment provider}

Clark Dental is proud to be so much more than the supplier of world-class equipment and furniture. We are dedicated to supporting our clients and ensuring that they can get the very most out of their cutting-edge technologies.

For every piece of equipment we offer, we streamline the entire journey, from product selection to installation, team training and ongoing aftersales support. We're here to help maintain technology where necessary, with an extensive and highly experienced team of engineers on hand to keep everything running smoothly for minimal disruption to your patient care.

We provide a comprehensive service so you can count on us in every situation. We are more than just an equipment provider.

For more information call Clark Dental on 01268733 146, email info@clarkdental. co.uk or visit www.clarkdental.co.uk.

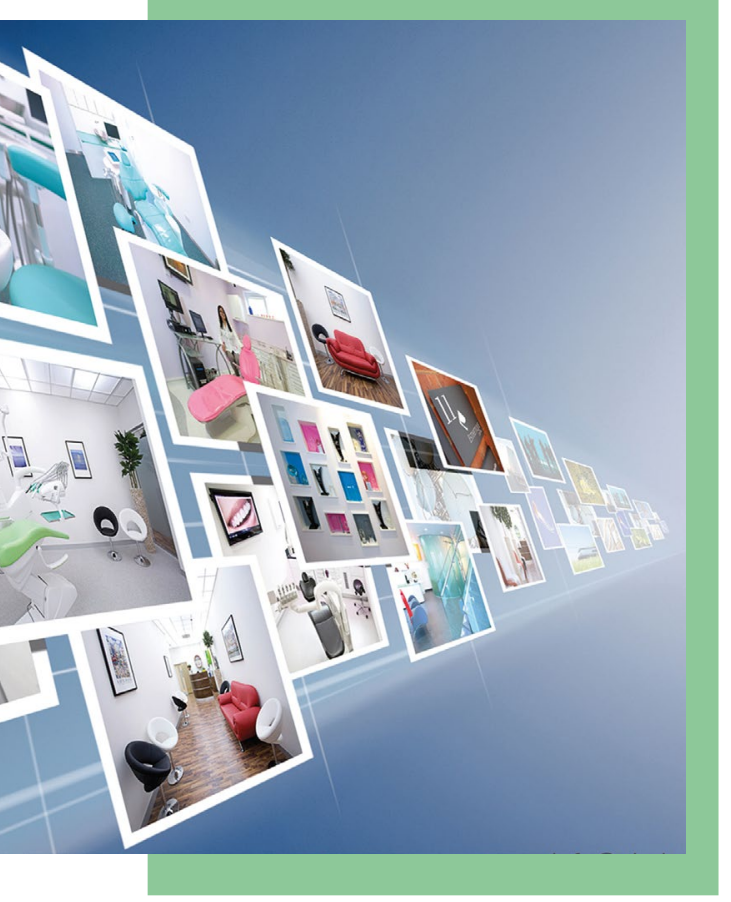

\title{
Next stop: growth
}

Make your next stop the British Dental Conference and Dentistry Show Birmingham 2022 and enjoy a fantastic introduction to a wide variety of topics to help you decide on your next growthgenerating move.

Professional development is a cornerstone of the dental profession, but there are so many pathways to progress that it can be difficult to know where to dedicate your focus. Whether it be facial aesthetics, or endodontics, periodontology, orthodontics or restorative dentistry, the 2022 show promises to showcase an unparalleled range of engaging subjects with over 250 seminars and workshop sessions to inspire you for your next challenge.

Don't delay and register your interest to attend today to access a wealth of information so you can choose the right area of focus for you and your practice.

The next British Dental Conference and Dentistry Show Birmingham will be held on Friday 13 and Saturday 14 May 2022, Birmingham NEC, co-located with DTS.

For more information, visit birmingham dentistryshow.co.uk, call 02073485270 or email dentistry@closerstillmedia.com.

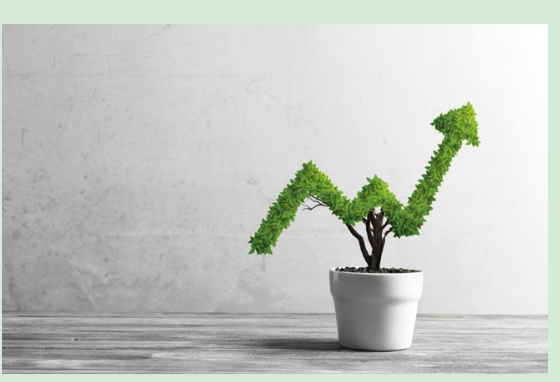

\section{Keep our waterways safe!}

Dental amalgam presents considerable danger to marine environments. The material has significant mercury content that is converted into monomethyl mercury in ocean water, which can damage both wildlife and humans who consume creatures that have ingested the contaminated water.

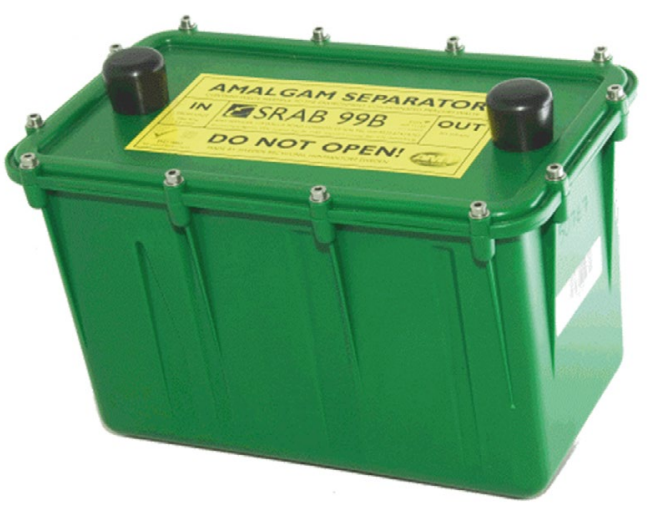

Make sure you protect our waterways against amalgam with the PureMotion amalgam separator from Initial Medical.

This BSI-accredited solution achieves up to $99.8 \%$ removal of amalgam from your waste water stream and has 'plug and play' fixtures that mean it can be simply installed, even on existing waste water systems.

Plus, as part of Initial Medical's service agreement, your PureMotion amalgam separator will be professionally installed with no need for any downtime and regularly replaced during servicing. This ensures you can significantly minimise the threat that amalgam from your practice poses to the environment.

To find out more visit www. initial.co.uk/medical or call 0870 8504045 . 